\title{
Research on the Trust Foundation of Reputation Mechanism of Food Quality Legal System with High- quality Development
}

\author{
Ziyi Yang \\ Quality Development Institute of Kunming University of Science and Technology \\ Kunming, China
}

\begin{abstract}
The development of media changes the pattern of information discourse power. It has had great impact on the trust of existing food quality information and the legal trust order. The trust foundation of the reputation mechanism of food quality legal system has quality defects. It is necessary to construct a standard mechanism for public discourse power to improve the quality of information trust, and to construct a standard mechanism for discourse power of functional departments to maintain the quality of legal trust. Through the construction of the discourse right regulation mechanism, the trust foundation of the reputation mechanism of food quality legal system is maintained.
\end{abstract}

Keywords-food quality legal system; high-quality development; reputation mechanism; trust foundation

\section{INTRODUCTION}

High-quality development is the fundamental choice to solve the main contradictions in society. In other words, it is necessary to respond to the need for the construction of the reputation mechanism of food quality legal system from the perspective of the high-quality development of the reputation mechanism of the food quality legal system. The item "reputation mechanism of food quality legal system" is interpreted from the literal level under the perspective of high-quality development, which is the higher level and higher demand social effectiveness goal proposed by the regulation mechanism of food quality information discourse rights. From the perspective of the logical path of the reputation mechanism, it is to strengthen the basis of trust trough the legal regulation of the discourse power of food quality information, improving the authenticity of the information related to food quality and the timeliness of dissemination.

\section{QUESTIONS}

The media is a kind of "decentralized" information communication medium, and it provides technical support for the public to pass the subjective cognition of food quality information. Due to its low entry threshold and rough information transmission and filtering mechanism, the public's desire to express their own perception of food quality has been greatly satisfied, and the previous situation of simply receiving food quality information has been changed. The public has become the participant in information dissemination, and the public discourse right has been strengthened. In addition, the spread of food safety information is transformed from a single communication mode that is exported by the government and received by the public to an interactive communication mode between the government and the public. It is more difficult to control the transmission path and flow of food quality information. The operation of the preset information standard mechanism under the existing food quality response mechanism was frustrated, and the discourse power of functional departments was weakened.

Under the new information structure, the balance of food safety information order has been broken. The public discourse power is not effectively regulated. The food quality information tends to increase, and a large amount of inferior information is generated, which has a negative impact on the trust of food quality information. The discourse power mechanism of the functional department does not adapt to the new pattern, and the food quality legal system falls into the dilemma of weakening efficiency and losing stability, which impairs the public's trust in the existing legal system of food quality.

The food quality information trust and food quality legal trust constitutes the trust foundation of the reputation mechanism of food quality, which is an important guarantee for its effective operation. The defect of trust quality will have a negative impact on the operation of the reputation mechanism, and even push the entire food quality legal system into the "Tacitus trap", creating a trust dilemma in mechanism operation. That is to say, no matter what mechanism the functional department takes to conduct the regulation of food quality problems, the public will question its rationality.

\section{OVERVIEW OF THE REPUTATION MECHANISM OF FOOD QUALITY LEGAL SYSTEM}

The reputation mechanism is a part of the food quality legal system, which is different from other regulations in the rule of law system. Its system design fully considers the cost factors of social governance. There is no need to rely on external forces to intervene in the mechanism design mode, 
which reduces operating costs. In addition, the operation of the reputation mechanism indirectly promotes the orderly operation of other mechanisms of food quality, enhances the social effectiveness of the food quality legal system, and saves the overall operation cost of legal system.

The trust foundation of the reputation mechanism of food quality legal system mainly includes information trust and legal trust. Information trust is premised on the universal truth and accuracy of food quality information. The degree of quality is intuitively reflected in the extent to which the public generally believes that food quality information in the process of information flow is real information. Legal trust is mainly based on the soundness of food quality legal system. The degree of its quality is mainly manifested in the operation effectiveness of the food quality legal system and the general support and cooperation of the society in the operation of the system.

The construction of the reputation mechanism of food quality legal system is a systematic project, and any quality defects consisted of the trust foundation will have negative impact on the effective operation of the reputation mechanism. Under the new pattern of discourse power, the lack of mechanism for the public's discourse power has led to an increase in the intensity and breadth of food safety rumors. The efficiency of the food quality information mechanism has decreased, resulting in defects in the quality of information trust. The gaps in the discourse power mechanism of functional departments have emerged. The defects of the existing legal mechanism of food quality exposed in the food quality incident are further amplified, resulting in the quality defects of legal trust. Therefore, through the construction of the system, regulating the public discourse power and the discourse power of the functional departments, and improving the quality of information trust and legal trust are the ways to maintain the trust foundation of the reputation mechanism.

\section{THE Discourse POWER OF THE PUBLIC AND INFORMATION TRUST}

Information trust is based on high-quality food quality information, but rumors often become the main body of information flow in the absence of social public discourse power. Therefore, reshaping the trust of information requires constructing a normative mechanism for the discourse power of the public to regulate the various aspects of the flow of rumors.

\section{A. Analysis on the Formula of Rumor Flow of Food Quality Information}

With the propaganda formula of communication rumors, this paper analyzes the influencing factors of all aspects of the flow of food quality information rumors, and clarifies the specific objectives of the normative mechanism.

1) Analysis on $R=i^{*} a$, the formula of food quality information rumors: $\mathrm{R}=\mathrm{i}^{*} \mathrm{a}$, namely, the intensity and breadth of rumor spread $=$ the importance of the event to the public $\times$ the degree of ambiguity of the event information.
As a variable in the formula, $i$ represents the general judgment of the public on the importance of the events involved in the rumors. The food quality is related to the vital interests of the public. In the process of analyzing the mechanism of food safety propagation mechanism, $i$ value is basically constant, which is equivalent to the quantitative to some extent. To put it another way, the intensity and breadth of the spread of food quality rumors depends mainly on the value of a. It can be known from the formula that the spread intensity and breadth of food safety rumors are positively correlated with the ambiguity of food quality information content. The more ambiguous the information is, the greater the intensity of rumor transmission and the wider range of transmission will be. If a value is zero, that is, the supply of food quality information in all aspects of the communication process is clear and sufficient. The information content is in line with the society's universal quality standards for food safety information, and the food quality information required by the public is maximally satisfied. The value $R$ is also zero, and food quality rumors will not occur. Therefore, the specific goal of the normative mechanism is to reduce the value of a as much as possible. In the case of a relatively constant value of $i$, the degree of ambiguity of food quality information can be reduced as much as possible, so as to effectively improve the food quality information of all aspects of the flow.

2) Re-analysis of $R=i * a / c$, the formula for food quality rumors: The formula of $\mathrm{R}=\mathrm{i}^{*} \mathrm{a} / \mathrm{c}$ points out that the spread of rumors depends not only on the values of $i$ and a, but also on the value of $\mathrm{c}$, that is, the strength of the public's ability to criticize food quality information. If the level of social food quality cognition is generally maintained at a high level, or if the public generally has the ability to reasonably identify and criticize food quality information, the spread intensity and breadth of rumors will be weakened. From a deeper level, the quality of food quality information that can be obtained for normal life is not high, or the quantity is lacking, or the degree of ambiguity is high, which is the root cause of the general lack of rational ability to identify and criticize food quality information. After all, food quality rumors can answer the confusion of the public. When there is a lack of accurate information, for the sake of self-interest, they often choose to believe that rumors are true information. Therefore, the specific objectives of the normative mechanism should also include the rational improvement of food quality and the improvement of information capacity among the general public, and they are the main participants in the rumor flow.

\section{B. Constructing a Standard Mechanism for the Discourse Power of the Public}

As a party with relatively insufficient food quality information capabilities, the public often uses subjective comparisons or follow-up methods to identify information in order to make the most self-interested decisions through a relatively rational blind choice. In this case, food quality 
rumors will be constructed consciously or unconsciously by individual potential stakeholders, and the public will subconsciously or consciously choose to believe that their information is true and disseminated. This provides the necessary supports for constructing a normative mechanism.

Food quality information is distributed in all aspects of the food industry, and it is professional and concealed. The cost of integrating food quality information is high. It is not expected to rely on the public to integrate information resources. However, with the proper integration of food quality information, it will become a non-competitive public product with a wide range of social benefits. At the same time, increasing the use of food quality information by a social individual will not bring about an increase in the cost of information supply, that is, the marginal cost is zero. The use of food quality information by certain social individual will not affect the quantity and quality of other social individuals, that is, the cost of marginal congestion is also zero. This provides rational support for the cost of the normative mechanism.

Considering the above factors comprehensively, the standard mechanism should include three parts: the caliber standard mechanism, the flow standard mechanism and the decoding standard mechanism, so as to effectively regulate the social public discourse power in the whole process of food quality information flow. The caliber standard mechanism guarantees the quality of the output information at the source of the information; the flow standard mechanism guarantees the quality of the information in the process of information flow; and the decoding standard mechanism provides assistance to the audience in understanding the high quality of the information.

\section{THE DisCOURSE POWER OF FUNCTIONAL DEPARTMENTS AND LEGAL TRUST}

Legal trust is the product of the accumulation of public experience. The public integrates past direct or indirect experience, positive or negative information and uses it as a criterion for trust in existing legal systems. The legal system produces social effects, and the value concept it carries is generally recognized by the society, and it will accumulate as a positive experience and become a positive asset for maintaining the legal trust of food safety.

\section{A. Current Status of Food Quality Legal Trust}

The food quality legal system of "Food Safety Law" as the core is affected by the development of the food industry and has the characteristics of short duration of existence. The substantive expiration date of the system is earlier than other laws. However, due to the weakening of the discourse power of the functional departments, the sensitivity of the response mechanism of the legal system is reduced, which leads to the highlight of the legal changes in the legal system of food quality in China. That is, when the system changes are not suitable or the change is lagging, the system operation is essentially invalid, and the efficiency of the system is neglected. The change is advanced, blindly pursuing the system update, and ignoring the stability of the system. If it is in such an objective state for a long time, the law will gradually lose the active support of the public in the application process, and the normative functions such as the guidance, evaluation, prediction, education and compulsory of the law cannot be exerted through the existing system, and exist as a negative asset of legal trust. To solve the above problems, it is necessary to further improve the standard mechanism of the discourse power of the functional departments, and to make up for the defects exposed by the existing systems in order to maintain the universal legal trust in food quality.

\section{B. Constructing a Cycle Management Mechanism of Food Quality Legal System}

The main task of improving the standard mechanism of the discourse power of the functional department is to construct a food quality legal system cycle management mechanism (referred to as: legal cycle management mechanism). Through the operation of this mechanism, the cycle law of the system is ascertained. The system change management can be carried out in a timely manner to provide a high-quality legal basis for legal trust.

The food quality legal system is limited by the law of the "bathroom principle" of policy implementation failure, and has periodicity. Therefore, the legal cycle management mechanism should be designed in accordance with the specific conditions of different stages. In the initial stage of the system operation, due to the low popularity of the relevant food quality legal system, the judicial personnel and law enforcement personnel also lack practical experience. And the failure rate of the system operation is high. At this stage, the social law enforcement is actively carried out, and it has become the main task of legal cycle management mechanism to organize judicial and law enforcement staff to carry out on-the-job training. In the middle stage, the public's familiarity with the system regulations has increased, and the system operation has been generally supported by the public. The judicial personnel and law enforcement personnel have gained experience, and the failure rate of the system operation has decreased. At this stage, the main tasks of the legal cycle management mechanism is to organize practical workers to carry out experience exchange, listen to scholars' research results and investigate public suggestions on the system. In the later stage, the objective situation of the system operation changes, and the failure rate is getting higher and higher, that is, the system cycle is about to arrive. The rationality of the existence of the food quality legal system in the cycle is virtually ineffective. If it is not abolished in time, it will be transformed into a negative asset that the food quality legal trusts, and then has a negative impact on the food quality legal system. At this stage, the main task of the legal cycle management mechanism is to check the continuity of the food quality legal system on the premise of ensuring compliance with the legal stability principles, and to put forward specific deposit and withdrawal recommendations for the formulation institutes combining the specific application practices with social cost considerations. 
Constructing a scientific legal cycle management mechanism, timely grasping the failure rate of the specific operation of the food quality legal system, timely alleviating the negative impact of the system cycle attribute on the food quality legal trust mechanism, and ensuring the efficiency of existing food quality legal system through cycle management are the perfection of the legal authority of the functional department to maintain legal trust.

\section{CONCLUSION}

The main contradiction in Chinese society has changed from the contradiction between the growing material and cultural needs of the people and the backward social production to the contradiction between the people's growing need for a better life and the development of inadequate imbalances. High-quality development is the fundamental choice to deal with this shift. High-quality development requires food quality information to meet the needs of the people's better life, and can stimulate the balanced development and full development of food quality. This paper is based on promoting the balanced development and full development of food quality, in order to serve the needs of the people's better life. In a word, based on the guidance of the concept of high-quality development, focusing on the discourse power structure of the public and functional departments, the optimization of the normative mechanism of the discourse power of food quality information is conducted. Starting from the trust foundation of the reputation mechanism of food quality legal system, the reputation mechanism of food quality legal system is further improved to promote the legal process of food quality.

\section{REFERENCES}

[1] Huang Tao. Three hurdles beyond the "Tacitus Trap" [J]. Hongqi manuscript, 2014 (12): 29. (in Chinese)

[2] Guo Xiaoan. The propagation and governance of network rumors [J]. Theoretical Exploration, 2014 (6): 53-57. (in Chinese)

[3] Lei $\mathrm{Yu}$. Trust foundation of reputation mechanism: crisis and reconstruction [J]. Management Review, 2016(8): 225-237. (in Chinese)

[4] Wu Dezhi. Rumor,Crisis of Legal Confidence and Cognitive Logic [J]. Law Review, 2015 (5): 69-78. (in Chinese)

[5] Zhang Xin. The new media, public participation and the pressureinduced legislation [J]. Hebei Law Science, 2016 (10): 90-101. (in Chinese)

[6] Lv Ting, Yi Zhongyi, Ying Ruiyao. Information supply and food safety risk management in new media environment [J]. Jianghai Academic Journal, 2017 (3): 82-87. (in Chinese)

[7] Wu Yuanyuan. The trust fracture and institutional countermeasure of co-governance in food safety governance $[\mathrm{J}]$. Modern Law Science, 2016 (4): 60-72. (in Chinese)

[8] Wang Chenguang. Reflections on some basic theoretical issues of food safety legal system [J]. The Jurist, 2014 (1): 37-43. (in Chinese)

[9] Ma Xinfu, Yang Qingwang. Preliminary discussion on legal trust [J]. Hebei Law Science, 2006 (8): 10-14. (in Chinese) 